\title{
“My Grandparents Used To Flirt Right There!" Active and Experiential Learning for New Teacher Professional Efficacy across Cultures
}

\author{
Dr. Ed Harrison \\ Dr. Verna McDonald \\ Assistant Professors, School of Education (UNBC) \\ NW Terrace Campus, 4837 Keith Avenue, Terrace, B.C. V8G 1K7
}

\begin{abstract}
This teacher education inquiry evolved through the collaborative practice of four faculties in a conceptual framework of: cultural safety, active and experiential learning, and catching our professional insights - looking backward and forward together: we construct. We are deepening our professional and cultural insights together as a program and as new educators, not repeating a catalogue description. The authors are teacher educators who have worked with a two-year Bachelor of Education program in rural, northern British Columbia, Canada.
\end{abstract}

The purpose of studying the B. Ed. program is to: 1) foster higher graduation rates, particularly with First Nations students; 2) develop self-defined classroom effectiveness with new teachers; and 3) increase retention of graduates in northern communities. Our research question is: Are we on purpose, doing these 3 things?

The theoretical framework includes concepts of: cultural safety, active and experiential learning, and teacher professionalism cross culturally. We share program examples, scaffolded throughout the four semester program to build teacher leadership qualities, in both specific academic areas and in navigating interwoven cultural spaces, including classrooms.

Our experience has been that: culturally relevant, active and experiential learning can bridge the colonial trauma dynamics within a diverse cohort, while providing developmental supports, and modeling teamwork for new teacher professionalism in practice with our culturally embedded teachers and children. In this collaborative paper, we investigate data on the initial cohort size, retention and graduation rates, active teaching, and some of the active and experiential learning processes that emerged as successful in the northwest UNBC cross cultural teacher training program for elementary teachers.

"My grandparents used to flirt right there!": Active and experiential learning for novice teacher professional efficacy across cultures

The purpose of studying our B. Ed. program is: to foster higher graduation rates, particularly with First Nations students; to develop classroom effectiveness with students across cultures; and to increase retention of graduates who are teaching in northern and rural communities. In this collaborative paper we investigate data on the initial cohort size, retention and graduation rates, active teaching, and some of the active and experiential learning processes that emerged as successful in the northwest UNBC teacher training program for elementary teachers.

\section{Introduction}

Who The first five UNBCB Ed cohorts in Terrace.

What Successful completion through effective teaching, ours and theirs.

When Two-year B Ed program starting in 2007,to graduation, May 2017

Where UNBC, NW campus, Terrace, BC, Canada

Why Four culturally committed educators wanted to see all children, on and off reserve, better served in our historically under-served "post"-or neo-colonial area; and to address both the education gap, and the "education debt" (Ladson-Billings,2006) that exists here to the present.

How Our current focus is on cultural safety, professionalism, and active and experiential learning. In the first years of our new teacher education team, we often travelled on territory to meet with First Nations and educational groups throughout the northwest. What we heard and learned, echoed our own experiences. 
We began the program in 2007 with four full-time faculty that encompassed provincial, national and international cross cultural and education experiences(one Metis faculty member, two females and two males, all English speaking; two bilingual faculty, all four currently middle class, able bodied and heterosexual).

An important aspect of our personal, professional and cultural growth has been our ten years of teamwork, with four of us meeting formally on a monthly program basis, plus meeting around research, special events, or workshop goals, presenting at conferences, publishing together, and talking frequently, informally. In all of our work together it is the cohort results in the northwest that we are most often discussing. We were thus constantly encouraged towards active, on-the-land, and culturally experiential learning with the diverse new teacher candidates for their deeper understandings in taking key elements of professionalism into varied settings with diverse children.

\section{Theoretical Framework}

The theoretical framework of this project is based on the concepts of: cultural safety, active and experiential learning, and teacher professionalism cross culturally.

\section{Cultural Safety}

Meeting northwest student needs arising from the current sociopolitical context requires a great deal of attention to an agenda of cultural safety. Hence, the central concept on which our faculty contributions converge is cultural safety in teacher training. The faculty have adapted the original New Zealand nurses' definition of cultural safety to meet the needs of the northwest B. Ed. context as follows:“...cultural safety may be identified with effective cross-cultural teaching, or the absence of unsafe practices, actions and reactions. In the context of public, education the definition of cultural safety refers primarily to the cultural identity and well-being of groups" (Harrison, Lautensach \& McDonald, 2012, p. 3).

- "Unsafe cultural practice is any action that diminishes, demeans or disempowers the cultural identity and well being of an individual" (NAHO, 2006) or group. Cultural safety may be identified as actively effective teaching across cultures, or the absence of unsafe practices, actions and reactions. For new teachers having both safe and unsafe classroom experiences explicated allows them to understand nuances of student cultural context responses in classrooms, when both or either are new to them. For example, the residential school experience, or relocations of First People's, were unsafe in some way for most indigenous students. Today so is not seeing themselves in classroom literature and materials. A teacher conscious of building cultural congruence could actively address the current Canadian explorations of restorative justice, reparations, and Truth and Reconciliation recommendations. Classroom activities could include a variety of perspectives, using current classroom literature and media photos, and having students bring their own thoughts and experiences to the classroom activities. In the context of public teacher education the definition of cultural safety refers primarily to this active sense of current cultural identity and well-being of groups.

When we adapted the New Zealand nurses' definition from patient context to teacher context it summarized for us our response to major northwest events - the Residential School hearings, Truth and Reconciliation commission report, Treaty negotiation upheaval on unceded traditional lands, and global resource industries' many northwest proposals. We would add that the active participation of each learning community member is required, beyond the passive stance to racial identity that white students often grow up with and often are acculturated to maintain. The active de-construction, recognition and re-construction processes involved in cultural safety work require a new cognitive and social-emotional response both personally and professionally. Govier (in Regan, 2010, p. 44) described the preferred passivity as related to knowing just "enough to know we did not want to know more" due to the likelihood that "the truth we would face would be unpleasant and incompatible with our favored picture of ourselves".

At times any of the education students, faculty or staff may bump into visible and/or invisible coping strategies for deflecting engagement with inter-racial dynamics. These ways of deflecting and obfuscating one's cultural history in colonialism, and thus coping with contested identity and socio-historic contexts, may assist participants in avoiding the "need for restitution and redress, threatening our rather comfortable way of life" (Govier, in Regan, 2010 , p. 44). We constantly find new ways to navigate the cultural intersections as events bring new questions and dilemmas. Crucial, difficult, fierce, hard, or courageous conversations are noted by the Ontario Ministry of Education leadership team. 
They comment that "In the absence of courageous conversations, we may be able to put a veneer on the status quo, and effect change on the surface, but deep and lasting change will be virtually impossible" (Bulletin 2, Winter 2013-14).

For example, in one cohort dynamic the conversations with a faculty member and student around aboriginal epistemologies - who is a knower, how one knows, and who one can learn from - were becoming a power struggle, with open challenges in class. A student with some First Nations family and academic course work, exhibited resistant behavior, even sitting backwards. Lengthy and difficult four-way mediation meetings with the student, instructor, program coordinator and a student representative seemed successful at the time. However, when all four were not present, resistance returned back in class. A number of attempts resulted in a testy "basic compliance for a grade" situation, in the opinion of the aboriginal faculty member.

The teaching team often focuses on capacity building and the program's growth towards facilitating cultural safety for all student teachers and indigenous faculty. Cultural safety work reveals power imbalances, makes visible personal bias and institutional discrimination, and may mitigate the effects of colonization long term, when we can all get through our various resistances to new choices. Efforts to achieve cultural safety necessitate respect and trust, and they proceed along a continuum through the stages of cultural awareness, cultural sensitivity, cultural competencies, and ultimately to cultural safety (Ramsden, 2005). When successful these efforts are regenerative to all. While still in process (as with the resistant student unwilling to learn with an aboriginal instructor) the interactions can be draining of personal, family, fitness time, and both student and professor energies. Yet there is still the potential for moving forward culturally in unexpected ways for important change in the face of new developmental, professional and academic insights. The continuum is large and unpredictable. For example, the student representative joining the mediation discussions learned a great deal, commenting on the value of experiencing dense to subtle layers of cultural resistance years later.

\section{Active and Experiential Learning}

Education literature has many different definitions of active and experiential learning. One classic definition of experiential learning comes from Kolb $(1984$, p. 41$)$ "the process whereby knowledge is created through the transformation of experience. Knowledge results from the combination of grasping and transforming experience".

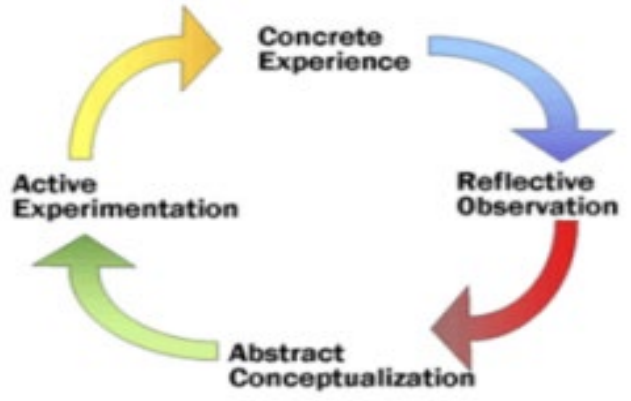

Kolb developed a learning cycle, represented briefly below:

(http://ctl.yale.edu/teaching/teaching-how/chapter-4-increasing-critical-thinking-and-motivation/active-andexperiential-learning).

The teacher education program is structured for concrete experiences of classrooms in each of the four semesters, three are student teaching experiences. We have learned that other field experiences with whole group teaching provide common language and ways of knowing. For example: the cohort was in a kindergarten class in a small First Nation's community for the activity of tracing children's outlines as they lie down on butcher paper in the hallway, and then sitting with them to talk as the children paint their outlines. We have found this kind of classroom experience together allows all candidates a common experience through which to discuss their own learning, their own assumptions, their own insights in vocabulary differences, developmental stages, self-efficacy, initiative and creativity, perspective taking and problem solving, bias and bracketing, gender dynamics, and many other classroom elements they would not otherwise have, to relate to and learn from as a cohort over time. B Ed students can start to see and experience that teacher growth is just as lively as children's growth and equally visible. Culturally, the response to visiting First People's contextualized learning spaces has been profound. 
In one example, a teacher candidate proudly showed us photos of her family, displayed in leadership roles around the K'San museum in Hazelton. At the Prince Rupert cannery a number of B Ed students shared family stories, including the story that became part of the title of this paper - that is, the spot where the cohort was standing was also where her grandparents used to flirt while working in the cannery many decades before.

When she went home, she took her family to visit with their grandparents. Many more stories were shared. She had tears running down her face in class as she described the joy in sharing this side of her family with her own children - the strength, love, resilience, and playfulness of those times would not have filled our campus classroom without that experience together in the cannery. A powerful social studies unit was born, and a new awareness of the "funds of knowledge" that students living in apparent poverty, yet rich with experiences, may bring with them, and enrich classrooms with through their sharing (Moll, 1992).

It is common in our area that thinking about students unlike themselves, the new teacher is "rudderless", working with families in a different economic world. For example, a graduate came to discuss a school re-combination of working and poor indigenous students from social housing contexts, with middle class professional families from a French based program. The new teacher was seeing a cultural reality transformed from imagining such a context, to realizing that this was a lived experience for his students with him as the leading change agent - or not. His decision was to pursue graduate work for deeper understanding of these dynamics.

One way to transform a class of children or adults is in using "active learning strategies [to] get students working with course material" in many configurations from independently to cooperative groups or whole class activities. "Active learning strategies, unlike open class discussion, are timed, structured, and designed to give students a chance to learn by acting on a specific piece of content in a specific way" (http://ctl.yale.edu/teaching/teachinghow/chapter-4-increasing-critical-thinking-and-motivation/active-and-experiential-learning).Students are much more likely to learn material actively, rather than being asked to absorb it passively. A well-designed active learning strategy has the following characteristics:

1. "Every student is acting on the material either individually or with others.

2. The timeframe is clear and relatively short.

3. The goal of the activity is clear, meaningful, and uncomplicated.

4. The task of the activity itself is clear, feasible, and uncomplicated.

5. The nature of the end product - be it a list, an answer, a choice, or a structure - is described unambiguously"(http://ctl.yale.edu/teaching/teaching-how/chapter-4-increasing-critical-thinking-andmotivation/active-and-experiential-learning).

Active and experiential learning based on "the concept of 'active pedagogy' in the context of the often static classroom is considered, along with challenges and advantages. Scaffolding student successes in experiences relevant to future roles in teaching, can be key" to new teacher success (Harrison \& McDonald, 2015).

The concept of active learning has a long history within western education. Such educational philosophers as: Wollstonecraft, Rouseau and Dewey, all pay homage to the actively involved student (Gutek, 2005). In formally organized educational settings it appears under many program titles: student-centered learning, hands on learning, Montessori Education and project based learning, for example. All reflect the premise that students should be directly involved in constructing knowledge based upon their participation in a thoughtfully contextualized learning experience. Coffey defines it this way:

Experiential education is an instructional approach based on the idea that ideal learning occurs through experience. Learning tasks require the active participation of the student in hands-on opportunities and must connect content to the student's life. Experiential education combines active learning with concrete experiences, abstract concepts, and reflection in an effort to engage all learning styles (Coffey, http://www.learnnc.org/lp/pages/4967).

The experience itself may be supported by teacher actions such as: scaffolding the learning experience, reflection, setting boundaries, posing questions, retell, or critical analysis and synthesis. In education, the terms associated with active pedagogy are often vague and left largely to the interpretation of the instructor and students. Case and Daniels (2016) point out this vagueness about the term critical thinking: Even educators who try to engage their students in thinking critically about content are often hampered by vagueness about what that means. Without a clear understanding of critical thinking, teachers are likely to adopt a superficial approach, have significant gaps in treatment, or proceed ineffectually, if not counterproductively (p. 53). 
An example with one cohort involved the question of when to de-construct with them the deeper layers of analyzing and adding to the learning experiences they are involved in, and when to see if they do the deeper thinking on their own (with the possible outcome they accept misinformation or one-sided perspectives, without the professor adding accurate information, questioning, or otherwise leading into the deeper thinking).

As Case and Daniels (2016) warned it is very important to be sure students experience what critical thinking means in action. This, however, is a challenge when applied to the teacher education program at the Terrace campus in the Pacific Northwest where so many students have had to cobble together their prerequisite programs. They may have taken a mixture of what was available as distance or on-line courses, compressed summer courses, college courses, face to face courses, and so on. Few have experienced one campus, full time, face to face, coherent programs. Our program has been an evolutionary one from the very first day. The cross-cultural nature of it has been the central driver of the pedagogy that has become associated with the program. On the one hand there is the western conception of post-secondary education: given that the program has been organized within, the structure of the University of Northern British Columbia, under the authority of the B.C. College of Teachers (now Teacher Regulation Branch). The course offerings at our campus follow the main campus(http://www.unbc.c a/calendar/undergraduate/education\#elementary).

Courses offered at the campus have been interpreted within each individual's frame of reference. This was established from the beginning: that the program should reflect the students who attend the schools in the school districts that we would serve. However, some schools in the region have as many as $98 \%$ of students who are First Peoples, while others are as low as $3 \% .{ }^{1}$ Various immigrant groups comprise the remainder. UNBC has offered two education courses related to First Peoples: Education 346 and Education 446. These two courses were designed to provide teacher candidates with a foundation of knowledge as they begin to learn with students of Aboriginal descent more equitably. (2) While the two aboriginal content courses are important in and of themselves they may not address the broader issue of non-aboriginal teachers teaching aboriginal children. The historic and current context of both groups should be made explicit in regardto the human and classroom dynamics - which impact groups in schools differently. It also must be recognized that $33 \%$ of our teacher candidates have been of Aboriginal descent: Cree, Gitxsan,Haida, Haisla, Metis, Nisga'a, Sto'lo, Tahltan, Tsimshian, and Wet'suet'en First People's.

From the beginning, the cohort model was used in the program. The first day of the program has always opened with a welcome to the territory of the Tsimshian people of Kitusmkalum and Kitselas by an elder, matriarch, fluent speaker, or knowledge holder. After this event the students are asked to meet at the confluence of two rivers: the Kitsumkalum and Skeena. This meeting place is on the land of the Kitsumkalum people and is sandwiched between the Canadian National Railway and Highway 16. In the background are the community buildings of the Kitsumkalum people and the sound of the river. In this meeting place a circle is formed and an elder talks of the meaning of education to the people and of its importance to the hopes and dreams of the children our students will teach. Through this experience a connection is established between the Aboriginal people, both in the area and within their own cohort, what their learning will be about and the importance of the land to identity. There is also time to think and reflect on what they themselves believe about working with Aboriginal people. Following the traditional welcome at the river, we offer a lunch of soup made by faculty(to begin to build cultural understandings as action). In our local aboriginal cultures a "bottomless" soupbowl is part of the feast tradition. It is important to recognize that the cohort will also complete its two-year journey with Faculty made soup and a visit to the place on the river that students visited on the first day, symbolically completing the circle. Through this act we illustrate the concept of the community of learners, indigenous and settler, working together toward a common goal. In some years we have added a more overt component to the day in having a teacher from the local district teach students to do some daily physical activities: this event is highly participatory and has the teacher candidates physically work together. Physical development is generally easier for new cohorts to address together than examining their very different cultural development. Over the course of the two years the cohort will reference this day many times.

The events of the first day are augmented throughout the first term and added to in the multiple field trips which the cohort takes as part of practicum and coursework experiences. Each field trip is designed to focus on the successes in cross cultural teaching in the Pacific Northwest. One field trip, for example, goes 150 kilometers to Prince Rupert and visits the Museum of Northern British Columbia where two cultures (settler and Tsimshian) are displayed. On one occasion a student reflected on a piece of clothing that covered a wooden leg. 
The wooden leg was a replica made after the carver saw an early British captain's leg, when the ship visited the Nass River. Telling the story that went with the artifact his way, the student said that this piece had been in his family for many years: a living, unplanned, connection making a sudden appearance in the midst of less personal artifacts that surrounded the students.

Our student re-created a historic large scale event, which brought from concealment the story behind the leg. In that moment other questions emerged about the other artifacts and what they were concealing in terms of power relationships. In this way the title of this paper emerged through the last part of the field trip when the cohort visited a cannery, now turned into a museum. The field trips lay a canvas for student's questions, to investigate as they move through the program. Choy describes a situation which is analogous in discussing transformational learning:

"To validate meanings for the organizational purposes, members of each community of learners shared their interpretations of the meanings they developed by engaging in active learning and rational discourses. They critically analyzed and contested their belief systems, current organizational practices, and cultures in light of the new knowledge, understanding, and perspectives" (Choy, 2009, p. 69).

Questions that emerge from the field experiences may be transformed in the courses and seminars that run parallel to the field trips. They are also the forum in which student or professor questions and thoughts begin to be explored. It is through this critically reflective practice and the social context that the student begins to be aware of what is required to become a teacher of children in the schools of the Pacific Northwest (Lilley, Barker \& Harris, 2015, p. 229).

The practice of reflection is indeed -practice. Students see each other in multiple venues, which encourages them to reflect on many cultural images and give voice to their cultural knowledge, interpretations and experiences through the varied dynamics from our fieldtrips. Reflection is a step towards capturing the perception at that time, and later the participants reflections on their experiences across time in light of new classroom experiences, and Course work, and the workshops within these courses, provide additional connections to the field trips. Wong provides a number of important findings which support the concept of multiple venues: "First, students have [a] tendency to think and write about reflection on their practicum experiences in a detached way...Second students face a number of issues in connecting their reflections from their practicum experiences to their own selfunderstanding ... third students have difficulty identifying and defining a sense of self as it relates to their practicum ... the final theme centres on reflection during crisis as a way for students to understand self and identity" (Wong, 2016, p. 5 -6).

The Foundations course, for example, uses in addition to the traditional European visions of education in the text by Barman and Gleason(2003). This text explores, from a historical perspective, the European and First Peoples experiences in organizing the school systems in British Columbia. Other events weave in broader community involvement with the students. For example, a math fair in which the teacher candidates develop 'mini-lessons' for the families who attend; or a poster session in the first of the Aboriginal courses (in whichthey display their understanding of First Peoples). One teacher candidate stated on one occasion: "I didn't know, and I suspect you don't know, how rich this area is with the culture of the First Peoples, this is a treasure" (cohort member, personal communication, November 07, 2016). She echoes Ryan when he states: It is in the dialogic and intellectual stance that is taken in relation to everyday practice as an element of social and cultural conditions, that change can be enacted both at a personal level and at a broader contextual level. In treating 'self' as a subject of critical study in relation to others and the contextual conditions of study or work, 'lifelong learning' can be fostered (Ryan, 2013, p. 145).

This would be the aim of the program - to effect lifelong reflection with respect to the candidates' ability to act consistently and make culturally congruent changes in their approach to teaching in the northwest. One of the key elements to ensuring consistency in the program is the faculty/ staff meetings that are held once a month. These meetings provide a forum in which the work of the faculty with the students is discussed. Shared beliefs around pedagogy and common themes are examined in light of the changes faculty feel need to be addressed. The meetings are where support is provided for further field trips and other student led events such as the literacy fair organized by the students in January. 


\section{Professionalism}

Professionalism in the current cohort work means several things to our team. The Apple-Inc dictionary definition is simply: "the competence or skill expected of a professional". We have added some aspects of mentoring towards this professional competence in collaboration with our teacher candidates.

First we are exploring "the powerful idea of capital and articulate its importance for professional work, professional capacity, and professional effectiveness" (Hargreaves \& Fullan, 2012, p. 1). New teacher efficacy in building this dynamic capital at individual, campus and career levels becomes essential to later classroom success.

In the face of the current complexity of teaching, moving into yet another learner role with rapidly shifting professional cultural identities can leave new teachers adrift and feeling like they have no culturally or professionally safe zone. In that complexity, important knowledge includes the fact that "systems that invest in professional capital recognize that education spending is an investment in developing human capital from early childhood to adulthood, leading to rewards of economic productivity and social cohesion in the next generation" (Hargreaves \& Fullan, 2012, p. 2).In this re-framing, the new teachers can see professional competency as they develop a more fluid teacher identity.

In the beginning of deeper reflection, students are learning that what you see and think can over-ride deeper perception, which takes in many ways of knowing. What we hold as our intention for teaching in the B. Ed. program - is having both the individual and collective focus simultaneously. It is in the stream of thinking being stopped and opening to the whole, that perception may emerge - against the background of knowledge that includes the stopping to reflect. Reflection can then unfold, as it has been allowed - as a new way of experiencing one's classroom. The teacher is then able to reflect on that moment and to do it concurrently with cognition: both emerging from and into the experience of the whole. Teachers do not think in the same linear way when the brain is fully integrated. For example, an individual child's tears are both a fragment of behavior, and a part of the whole, both require "classroom management". The actual response is different from the perspectives of the individual tears or the whole classroom. Is there a relationship between Paul's tears, and Mary's laughing? What do the children around them experience? Each child has different emotions and thoughts. How did the event unfold as it did - Paul crying, Mary laughing, and the group gathering around them? The teacher needs to see the whole and respond to the whole, even while their own questions and thoughts rapidly appear and change; some as actions to take, others as emotions, cultural questions, and so on. This may be some or all of dysconsious, unconscious or conscious processes. When student teachers understand and experience how shortchanged developmental goals are when teachers simply think linearly of classroom management and its details, they know they are expanding their own effectiveness through this deeper reflective work.

Secondly, the confluence of these trajectories, teacher identity and cultural identity, as reflexive and being practiced in a school context can be overwhelming for new professionals, and sometimes for their mentors. When they are part of each other's questioning, hear critical and deeply reflective conversations, and find identity fluidity as positive, there is much more likelihood that inquiry will continue. Solomon, et al, gave a practicum example of such a professionalism question for a student teacher involved in the production of a Christian play. The student struggled with his experience of the white teachers maintaining the cultural status quo, while progressive professionalism in his teacher education work sought his involvement with "concerns of religious and culturally centric programming" in a culturally "myopic learning environment" (Solomon, Singer, Campbell and Allen, 2011, p. 146-7).

Thirdly, the example of the play also raises the multiple layers of professionalism required as university faculty, practicum supervisors, classroom teachers and site principals, all engage with the new teacher and a classroom community. An ideal of maximum professionalism from all concerned may be difficult to attain in the very real intersection of cultures, human development, and individual academic goals of teacher education.Examples of these three aspects of professionalism follow.

1) Professional capital as professional work, capacity and effectiveness, towards a larger human capital. An example of this would be the intersections of knowledge that are consistently being built and drawn upon: knowing the territory house groups, building personal relationships in the villages or town, working with schools and district personnel, and understanding how they are connected with our student/s. Without this knowledge it is very easy to misunderstand the dynamics of a situation related to a particular student in the class. 
2) The professional confluence of teacher and cultural identity. A student, for example, who created a story about the Nisga'a Hobyiee celebration for a class, and who now has the beginnings of a book which she is intending to publish. This is about not only the student coming to a deeper awareness of her place within the classroom, school and the teaching profession; but more importantly the reaffirmation of her own cultural background, identity and efficacy.

3) The multiple layers of professionalism that are being addressed in teacher education. For instance the BC Ministry of Education and new curriculum implementation, which involves layers of School District personnel who are responsible for local implementation, principals of schools who want to ensure that the teacher candidates they hire are aware of the new curriculum, the Teacher Regulation Branch who watch over the students applying for certification, the faculty who teach the content areas and methods classes, and the students who are constantly testing to see how much faculty understand the expanded role of Indigenous material in the new curriculum. These layers of professionalism are all actively and explicitly explored in our B Ed cohorts.

\section{Methods}

Methods for an inquiry into program success have evolved from a reflective case study approach - with the NW UNBC teacher education program as the case. A "case study describes a single example of a phenomenon or experience involving individual, group, institutional, or social responses" (McDonald, 2009). Through this study we are tracking institutional data on program graduation rates, and informally tracking outcomes through school site visits post-practicum, continued connections and projects with graduates, and retention data for graduates in our northern communities. Currently in northwest BC, cultural, economic, and educational influences all change so quickly, acting on informal information is as essential to student success (children or adult students) as acting on formal data is. Another inquiry method informing our program development is workshops conducted with open-ended activities to gather information from other professors and instructors on cultural safety, and active, experiential learning. Each semester workshops are also conducted with classroom mentor teachers including these topics and new teacher professionalism (Zeichner, 2005).

Through our own cultural growth we are seeing the need for us to humbly explore indigenous scholar's work in Decolonizing Methodologies (Tuhiwai-Smith, 2006) and in Research is Ceremony: Indigenous Research Methods (Wilson, 2008). "Appreciating the differences Indigenous people have in terms of their ontology, epistemology, methodology, and axiology can lead to research methods that are more fully integrated with an Indigenous worldview" (Wilson, 2008, p. 20-21). It would seem to us that without making an effort to reduce some of the colonizing influences research has had and is having, in the period of time while capacity building with Indigenous scholars is occurring, decision making will again be led by white researchers and Western, Anglo or Euro-traditional worldviews. Our efforts in this regard have evolved another step with this research (in continual progress) around the question of improving northwest education outcomes for both student teachers and indigenous children they are teaching.

The methods involved are 1) situating the researchers (see faculty description), 2) defining key concepts (see theoretical framework), 3) acknowledging paradigms of constructivism and the nature of constructed human perspectives (ontology), 4) shifting reliability and validity to a focus with authenticity that allows us align with the complexity of teacher education: Ontological authenticity (enlarges personal constructions), educative authenticity (leads to improved understandings of the constructions of others), catalytic authenticity (stimulates to action) and tactical authenticity (empowers action). (Denzin \& Lincoln, 1994, p. 114)

5) gathering data from our program with the intentional values of finding, "in a good way", the next steps for stronger outcomes with both student teachers and our indigenous children.

We are purposefully moving towards being stronger allies in education, while using our faculty relationships to examine hegemony (dominance or competition) creeping back into our work, yet also retaining responsible and ethical leadership as educators. When we collide on, or with, our own or institutional issues we all hold the intention to be clear and also to actively repair relationships and grow together as individuals, professionally, and in the program. 


\section{Findings}

Data sources include: 1) program data on intake, retention and graduation numbers and aboriginal students; 2) web data on student graduation rates in Canada, in BC and at UNBC, and 3) administrator, mentor and supervisor comments on student professionalism (student teacher documents, mentor teacher workshops, and school site visits), and teaching and learning examples. Results of data collected indicate cultural safety was deemed relevant, important and achievable in the north; with continual and transparent efforts for change that are open, collegial and linked over time.

Active and experiential learning has been seen to be important to students and possible for busy professors when supported with resources, time and collegiality. Change was implemented in small ways at first, followed by increasingly complex, layered or distant field experiences. Professionalism develops more rapidly in pre-service teachers with professors who have explicit cultural safety as an intention, during active and experiential learning. Under these conditions new teachers take on responsibilities and contribute to the profession: with professional development workshops, new grade and school configurations, in curriculum development, and across languages and cultures.

Why is this important in our area? Table 1 (A) shows the success rate of the program over four cohorts. The number of Aboriginal students enrolled in the program as a percent has remained reasonably consistent while those successfully graduating have increased. Table 1 (B) indicates that the 3 year (DSTC)) program has successfully graduated students and that some of those students successfully completed the B.Ed. program. Overall the rate of Aboriginal graduation from the program exceeds those of UNBC as a whole, Table1 (C). Tables 2 (A, B and C) indicate the Indigenous public school student graduation rates in Prince George (the largest school district in north central BC) compared to Coast Mountain School District (located in the Pacific Northwest). It is our belief that, as our graduates are hired as teachers in local schools, their understanding, experiences together, and knowledge of Aboriginal students will contribute to an overall rise in northwest school district's Aboriginal graduation rate. The contextualization in cultural realities of both coursework and practicums facilitates the students' implementation of new BC curriculum with an intercultural focus.

Table 1 Education intakes and graduation rates, UNBC, NW campus: program data

A. Northwest B Ed cohort intake and graduation, and number of indigenous students (First Nations, Metis) in intake, and graduating

INTAKE Indig \% FN

\begin{tabular}{|c|c|c|}
\hline $\begin{array}{l}\text { Grad Indig } \\
\text { with }\end{array}$ & $\% \mathrm{FN}$ & $\begin{array}{l}\text { Grad } \\
\text { later }\end{array}$ \\
\hline
\end{tabular}

$\begin{array}{lccccccccc}2007 & 30 & 9 & 30 \% & 26 & 8 & 30 \% & 2 & 2 & 100 \% \\ 2009 & 31 & 11 & 33 \% & 25 & 8 & 33 \% & 1 & \\ 2011 & 16 & 6 & 38 \% & 14 & 5 & 38 \% & 0 & \\ 2013 & 14 & 4 & 28 \% & 12 & 3 & 25 \% & 1 & & 0 \% \\ 2015 & 13 & 4 & 30 \% & 12 & 3 & 25 \% & & & \\ \text { TOTAL S104 } & \mathbf{3 4} & & 32 \% & \mathbf{8 9} & \mathbf{2 7} & 30 \% & \mathbf{4} & \mathbf{2} & \mathbf{5 0 \%}\end{array}$

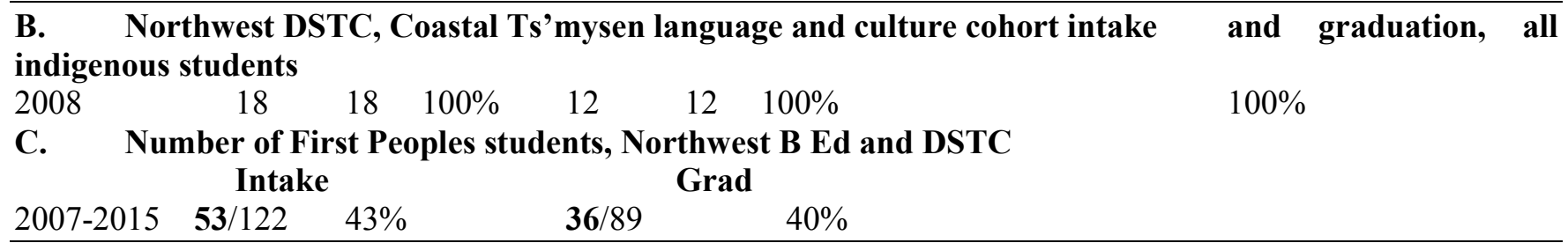

D. First Peoples graduates, UNBC total (Update magazine, Spring, 2016, p. 17). $6.5 \%$ 
Table 2 Aboriginal students and graduation rates in BC School Districts

A. Prince George SD

Aboriginal students in district

2016

$26 \%$

3249 students

$48.8 \%$ (compared to $81 \%$ non- $\mathrm{Ab}$ )
Aboriginal HS Graduation rate

2016

$61 \%$ (highest rate achieved so far)

\section{5}

B. Coast Mountain SD, Aboriginal student graduation rate

\section{2-13}

Aboriginal graduation rate

$40 \%$

2014-15

Aboriginal

$44 \%$ to $42 \%$
2012-13

All students graduation rate

$60 \%$

2014-15

All students

$68 \%$ to $68 \%$

Janssens, A. (July 30, 2013). Grad rates here lower than rest of province. Terrace Standard, page 1.

C. BC student graduation rate

Aboriginal students

2015

$63 \%$

Non- aboriginal students

2015

2010

$84 \%$

$54 \%$

2010

$80.5 \%(18-19 \mathrm{yrs})$

$92.5 \%$ (20-24 yrs)

2005

$62 \%$

BC (2005), at $62 \%$ overall,

with 10 SD below $50 \%$.

BC Goal-85\% aboriginal students by 2015 .

\section{Discussion and next steps}

The educational importance of this inquiry was particularly visible around the time of the Residential School Hearings and Truth and Reconciliation Commission. We continued to learn about intergenerational complex secondary trauma as evident throughout the northwest, with Dr. Linda O'Neil, of the UNBC Counseling program, and that such trauma layers continue to be highly impactful for public school and teacher education students enrolled in our area. Cultural safety is a primary consideration for the success of the students, and thus for the success of the future teacher. Teachers may also be impacted by complex secondary trauma, and in some cases their own primary experiences. They may also be working with families, colleagues, administrators and district staff impacted. We have seen active and experiential learning that is culturally relevant bridge such trauma dynamics within a diverse cohort, and increase our retention and graduate rates for Aboriginal students above the provincial norm. As experienced educators, we must provide constantly creative supports and scaffolding, as well as modeling and teamwork towards graduation, professionalism, and new teacher self-efficacy in classrooms throughout teacher careers.

A key aspect of our B Ed program development is addressing inter-generational colonial trauma in the northwest: a major disruption to the families, nations, and to traditional learning. The trauma often becomes visible around racial and ethnic background, and lived experience differences. While approximately half of the students starting the program are Aboriginal, the remainder is of European descent. This leads also to questions about the cultural backgrounds of the instructors: do they overlay biases onto the program given that three of the four faculties are European Canadians? Faculty spends considerable time in noticing such dynamics across the diversity spectrum, and acting to change them. As discussed in the example of the mediation request with the resistant student, bias also comes in with the new teachers. There are many layers that open the program to European epistemological bias: the first layer (motivation) is the desire to work with young people on a regular basis. Do you treat all students the same? 
They are not. Just as a student in a wheelchair needs different considerations than a student with a hearing loss, students who are first generation university students, have varied heritage languages, live in small villages, have often had the poorest available education and learning resources, are historically displaced, live in colonially imposed poverty; and/or experience bias, deculturalization and face both external and internal racism frequently have different needs than students raised with first language, economic, social and political privilege. The second layer is the recognition that you need a skill set to teach a class of students.

This skill set is unlike the traditional set that the Aboriginal child would have growing up in a village where the uncles and aunties take on the primary role of guiding and teaching the children. As we know from the Truth and Reconciliation Commission of Canada: A call to Action (2015) the disruption of the family and the traditional learning processes has been significant. The work that is done in our program (and others) is based upon traditional western assumptions about education: for example, most learning usually takes place in the classroom. The third layer is in how we bridge time and culture in such a manner as to encourage something of the traditional cultures to emerge within our program. This is reflected in the work of Buck- Morss, "If, as Marx argued, the ruling ideas have always been those of the ruling class, what value can the historical materialist find in those 'treasures' which make up the cultural inheritance?'(Buck-Morss, 1991, p. 288). She continues to discuss treasures of the past by referring to the work of Walter Benjamine: For without exception the cultural treasures he surveys have a lineage which he cannot contemplate without horror. They owe their existence not only to the efforts of the great geniuses who have created them, but also to the anonymous toil of their contemporaries. There is never a document of culture that is not simultaneously a document of barbarism" (Buck-Morss, 1991, p.288).

Buck-Morss (1991) poses a question that our faculty has tried to address in many ways through countless hours of discussion: is it possible to bridge the historical gap created by the residential schools, and the resulting intergenerational trauma? If it isn't, is it possible to mitigate their residual effects so that: a) Aboriginal students who are interested in teaching are able to do so in as culturally sensitive and knowledgeable a manner as possible? b) the teacher education program is able to offer Aboriginal students an opportunity to explore further their cultural heritage in an open and safe manner. For example, one of the students, after visiting a cannery, realized that it connected with the stories her Grandmother told her. From the visit and the stories, she created a unit for grade four students. The unit focused on photo's, visiting the site, family stories and written documents - the story of her Grandmother's time at the cannery.

Also for non-Aboriginal students creating a course of study that encourages a cultural understanding of the Aboriginal students they will teach, and also includes their own culture, and whose taken-for-granted assumptions are often questioned. This is offered as a shared journey between the Aboriginal students and the non-aboriginal students but one which, often is not an easy road to travel. One student, for example, brought Oolichan grease to class and explained its importance to the Nisga'a people of the Nass River. However, Oolichan grease has a pungent odor which some Westerners find difficult to be around.

The fourth layer involves the Northwest program as it emerged in Terrace, and that was established within the context of the UNBC, Prince George, Teacher Education program. The program itself is bound to the courses that were established as part of the regulatory process agreed upon by the main campus in Prince George and the BC College of Teachers (now Teacher Regulation Branch). Two conflicting concepts emerge: one is that the education system is designed to perpetuate the dominant image of education as a Western 'civilizing' program and thus bring all students into the dominant cultural understandings and goals, and second that the education system is increasingly culturally sensitive to the needs of all students. "Alternatives to Eurocentric education are necessary today in order to thwart the crisis-driven re-westernization of education involving the total subordination and control of knowledge within technological systems harnessed to market logics" (Baker, 2012, p.16).

Baker points to a significant problem. The broad interpretation within the Faculty has been to identify those areas of knowing that have a multiverse of understanding: that there is more than one way to know the world, and teachers need to be able to move back and forth amongst these ways of interpreting it, in order to search for the best way to both perceive, then work towards resolving a problem. Knowledge is not self-contained within a particular epistemology. We acknowledge that the answers to an educational problem encountered in our program are not necessarily solved by turning to a European based philosophical system. To ask the necessary questions, in a culturally safe context of two-way learning, is to begin to see what is important within the program, about the underlying logic and power relations that are emerging. 
Audrey Woods, a Gitxsan woman, captured the situation this way: "the Skeena River begins when it enters Gitxsan Territory and ends when it leaves the territory"; (personal communication, September 09, 2014).To a Western mind, rivers have a course and flow from source to mouth. It takes a while to realize the power of what she is saying about what Gitxsan know and how they know: that the river embodies their territory, identity, beliefs and values.

Santos identifies this as "'intercultural translation". "...intercultural translation consists of searching for isomorphic concerns and underlying assumptions among cultures, identifying differences and similarities, and developing, wherever appropriate, new hybrid forms of cultural understanding and intercommunication that may be useful in favoring interactions and strengthening alliances amongst social movements fighting, in different cultural contexts, against capitalism, colonialism, and patriarchy and for social justice, human dignity, or decency" (Santos, 2014, p. 212).

It is important that the instructors are open to recognizing alternate ways of knowing the world and incorporating them into their work with the cohorts. There has been an incremental growth of knowledge over the ten years the program has been offered. Our Aboriginal Coordinator (and program instructor) has been instrumental in supporting our efforts. But the working together of faculty has also been key to moving the program in a culturally safe direction. Faculty, for example, has written a collective paper about the program. Others have presented together in various venues (for example at Northwest Community College in Terrace, and a Teaching and Learning Conference in Prince George). Three faculty and the practicum placement coordinator enrolled in a Sm'algyax (Tsimshian language) course. We have talked with elders and worked with them. Janson \& Paraskeva described it this way: “ . ..there is no social justice without cognitive justice - related with the 'hegemonicity' of Western modernity that systematically belittled and regarded any reality beyond the global North as non-existent" (Janson \& Paraskeva, 2015, p. 951).

We are all working together with the intent of learning how to incorporate Aboriginal epistemologies into our program in as authentic a manner as possible, recognizing at the same time that we are a work-in-progress. The fifth layer would be the ways in which we have interpreted the program within each of the courses. For example, in the educational psychology class: Development, Motivation and Learning; students expect educational psychology with a focus on child development, and how to assess and build on children's skills. In Western research psychology rodent/behavioral studies are classic. Students do not so much expect to analyze their own development from many perspectives, and explore how to grow with communities inter-culturally. Beginning in September, 2016, the new BC curriculum implementation mandates inter-cultural competency, which requires an in-action developmental complexity of thinking while teaching.

The order in which we connect the academic content, the lived examples from the new teachers on field trips, and the classroom observations on Tuesdays; impacts how the new teacher candidates process and grow in all aspects of their own development (cognitive, cultural, emotional, linguistic, physical, and social). It becomes natural for them to lead from their strengths, while acknowledging areas needing further learning, just as they will lead their classrooms, and teach the children and families to do. They realize that building honest self-disclosure is for the learning of the cohort. Resistance is minimized as students choose their own examples, and levels of sharing, both oral and written.

The balance of classroom backgrounds also impacts this teaching and learning order - from most common to least - so that when only a few students are impacted the compassion and reflection to learn with them has already been established, even though their experience may be very different. For example, in one cohort we had two nationally proficient kayakers who made physical activity frequent, applicable to classrooms, engaging, and a constant stretching experience for all of the rest of us! Starting with the physical aspect of development made it easy for students to look at academic theories of physical development, their own continuum over time for physical development, and what they were observing in classrooms. Once that camaraderie was established in the area of physical development it was available for all aspects of development. When we got to theories of cultural responsiveness, competencies, relevance, and so on, students knew they would choose their own examples and be expected to share them, as well as be able to observe and discuss cultural dynamics in classrooms. This kind of scaffold learning seems key to having white students begin to engage cultural inquiry, and for Aboriginal students to feel safe to do so around new white people. We have been told by visitors and students that the open discussion of dynamics across cultures and generations has not been available to them before locally. 
One student told me she and her siblings did not get out of the car when her parents had business in town. It was not considered safe to do so. The choices of content and activities in the child development class (such as timelines, gender role trees, cultural photo album, I AM... poem, ethnic identity stages, multiple intelligences pie, sociograms) are then open enough to make the point that we are all at very different stages as adults also, and can continue to grow in all areas with collegial support. We consistently find that cultural development is the most varied aspect, and is in need of scaffolding for many students.

The dynamics arise across classes, and professors often collaborate to interrupt inaccurate, awkward, or acculturated understandings (as when two of us facilitate a field experience, community activity, or class guest speakers with activities).

The sixth layer is the subtleties of what is happening within the dynamics of the classroom. In an intercultural environment what instructors might think is happening often isn't. In several cohorts it had been noted that teacher candidates who are First Peoples sat in the same location all the time. Instructors came to realize that these students viewed the seats as their 'home territory': a place where they felt safe and secure. This is not to say that they will not move around to participate in class activities, but rather that they expected to return to the seat they occupy day by day. This view of the seat was common to both our large and small cohorts. It is important to recognize that to First Peoples in the northwest, territory and identity are very significant. A seat is more than a seat. One student in our cohort described it this way: "Our seating arrangement is like at the feast hall-you were designated where you would sit... We liked to come early so we had our place.... If we didn't sit together we didn't feel the strength when we didn't sit in the same place" (Harrison, Lautensach \& McDonald, 2012, p. 323).

It is these subtle intercultural experiences which happen before the instructor's eyes, yet often remain invisible to all. Instructors try to be very sensitive to the nuances of the group as we work to braid the biographies and cultures of the students who are before us, but it is inevitable that situations are missed. The important question that we consistently ask is: are we missing something? In one case of the seating arrangements it was very important for one teacher candidate. This student came late to a first class of the term. She said she felt isolated and alone, then indicated that she would be able to continue if she could return to her former seat. In the end others made room for her.

Merleau Ponty captured the situation in the title of his book "Visible and Invisible" (1968). The layers of intercultural experiences that appear in the cohorts are important to recognize, even the smaller nuances that at first seem insignificant. Developing an experiential knowledge based program in an intercultural environment requires more time and thought than current capitalist, financially status quo oriented (that is, the replication of social class through education resources), monocultural educational systems are often willing to fund. Deepening each of the layers in this environment requires commitment and risk. It also requires an extensive comprehension of the social, political and institutional processes that have an interest in perpetuation of the western knowledge base (Godlewska, A., Moore, J. \& Bednasek, C., 2010, p.436).

The sense of a direct responsibility emerges. A sense that once taking on the teaching role - the teacher needs to continue on with the reconciliation and restoration process, while dealing with their own issues - whether white guilt and blank spaces, indigenous questions and identity chaos, or other dynamics. This commitment is central to what we are doing now in assessing the program, new curriculum, and proposed new teaching standards. Does that direct responsibility, for decolonization in action, happen? How? what's next in this emerging and immediate evolution - of how teacher identity grows into a real contribution to this effort at northwest accountability for new lived realities. An active change, instead of just more media worthy words while preserving the funding levels, staffing levels, and curriculum content and styles that disadvantage non-European, non-home language English and non-middle class students.

Will BC, and the northwest in particular, choose real collaborative action in implementing this new curriculum or more political photo ops with regalia or elders, and staged political responses with no impactful and immediate change? The stakes are very high with so many new teachers, and their future lives potentially impacted by our choices now.

End notes -

1. The school districts which are served by the School of Education (Pacific Northwest Campus - Terrace) are: Prince Rupert (S.D. \#52), Coast Mountain (S.D.\# 82), Nisga'a (S.D. \#92) and Smithers (S.D. \#54). Nisga'a District school, for example, serves the Nass Valley which is largely occupied by people of Nisga'a descent. 
There are four schools in this district. StatsCanadahttp:/www12.statcan.gc.ca/census-recensement/2011/ $\mathrm{dppd} /$ prof/details/Page.cfm?Lang=E\&Geo1 $=$ CSD\&Code1 $=5949035 \&$ Geo2 $=$ PR\&Code2=01\&Data $=$ Count $\& S$ earchText $=$ New\%20Aiyansh\&SearchType $=$ Begins $\&$ SearchPR $=01 \& B 1=$ All\&Custom $=$

2. It is important to note that other programs in British Columbia do not offer two courses in Aboriginal Education for all students. Education offers students a general knowledge of Aboriginal peoples and Education 446 is an Aboriginal Epistemology course. These are required courses for all Bachelor of Education students.

3. This event was brought to the Northwest School of Education through Christine Eide and Kathy Eades.

4. The original professional group (NZ Nurses) of cultural safety is as follows: "The effective teaching of a person/family from another culture by a teacher who has undertaken a process of reflection on [their] own cultural identity and recognizes the impact of the teacher's culture on [their] own classroom practice" (NCNZ, 1992).

5. Notes and references for Table 2, p. 26

\section{Table 2 References}

\section{A. Prince George SD}

Northern aboriginal education symposium, February 26, 2016

https://www.sd57.bc.ca/school/abed/Pages/NAES.aspxAccessed on May 21, 2016

https://www.sd57.bc.ca/school/abed/About/Pages/default.aspxAccessed on May 21, 2016

http://www.princegeorgecitizen.com/news/local-news/documentary-puts-aboriginal-education-in-spotlight-

.1979058AAccessed on May 21, 2016

\section{B. Coast Mountain SD}

http://cmsd.bc.ca/wp-content/uploads/2011/08/CMSD82-2014-2015-Achievement-Contract.pdf Accessed on May 19. 2016

http://cmsd.bc.ca/wp-content/uploads/2011/08/CMSD82-2014-2015-Superintendents-Report-on-Student-

Achievement. pdfAccessed on May 19, $201642 \%$ of 5000 students in the district are aboriginal (homepage.cmsd.bc.ca)

\section{Province of BC}

http://www.cbc.ca/news/canada/british-columbia/aboriginal-graduation-rate-1.3383908Accessed on May 19, 2016

http://www.cbc.ca/news/canada/british-columbia/aboriginal-student-education-bc-improvements-racism-

1.3306014Accessed on May 19, 2016

http://www.statcan.gc.ca/pub/81-004-x/2010004/article/11360-eng.htmAccessed on May 19, 2016

Note: Canadian students appear to be graduating later than school districts would be recording data.

Statas Canada Data from 2011, shows 20-24 year olds have significantly higher graduation rates than "usual" 18 19 years at high school graduation. Canadians, 25-64 years, with less than high school graduation is $8 \%$ in general and $21 \%$ off reserve Aboriginal. That would indicate broadly, that Aboriginal students do pursue high school (and possibly higher education) later than non-Aboriginal students. In 2011 data above, $79 \%$ of $\mathrm{BC}$ Aboriginal adults had graduated from high school. In our decade of experience in teacher education in northwest $\mathrm{BC}$, we seldom have $18+4$ years $=22$ year old Aboriginal teacher candidates. http://www.statcan.gc.ca/pub/81-582x/2012001/tbl/tbld6.3-eng.htmAccessed on May 19, 2016

\section{References}

Apple-Inc. (2005-2014). Dictionary. Version 2.2.1.Association for experiential education. Retrieved from ee

Baker, M. (2012). Modernity/Coloniality and Eurocentric Education: towards a post-Occidental selfunderstanding of the present.Policy Futures in Education. Volume 10, Number one, 2012.

Barman, J. \& Gleason, M. (Eds.). (2003). Children, teacher, schools in the history of British Columbia. Detselig Enterprises Ltd.: Calgary.

Buck-Morss, S. (1991). Walter Benjamin and the Arcades Project.The MIT Press, Cambridge, Massachusetts. In progress

Case, R. \& LeRoi, D. ( 2016).Teaching elementary students the tools to think critically. In Case, R. \& Clark, P. (Eds.).The anthology of social studies for elementary teachers. Vancouver: The Critical Thinking Consortium. 
Castellano, M.B., Archibald, L., \& DeGagné, M. (2008). From Truth to Reconciliation; Transforming the legacy of Residential Schools. Ottawa, Ontario: Aboriginal Healing Society.

Choy, S. (2009) Transformational learning in the workplace. Journal of Transformative Education, Vol. 7 (1), p. 6584.Doi:10.1177/1541344609334720Coffey,H.Experientialeducation.Retrievedrom:http://www.1 earnnc. org/l ppages $/ 4967$

Denzin, N., \& Lincoln, Y. (1994). Handbook of qualitative research. Thousand Oaks,CA: SAGE Publications.

Godlewaska, A., Moore, J., \& Bednasek, C. (2010). Cultivating ignorance of Aboriginal realities.The Canadian Geographer, 54 (4), 417-440. Doi: 10.111/j.1541-0064.2009.00297.

Gutek, G. (2005) Historical and philosophical foundations of education. Upper Saddle River, New Jersey: Pearson.

Hargreaves, A. \& Fullan, M. (2012). Professional capital: Transforming teaching in every school. New York, NY: Teachers College Press.

Harrison, E., Lautensach, A., \& McDonald, V. (2012). Moving beyond the margins:

Culturally safe teacher education. Montreal, Quebec: McGill Journal of Education, Vol. 47, No. 3, p. 323-343.

Harrison, E., \& McDonald, V. (2015). Active and experiential learning with northern communities. Presentation at the Center for Teaching, Learning and Technology (CTLT) annual conference,UNBC, Prince George, BC. Sept. 2-3, 2015.

Janson,E. \& Paraskeva, J. (2015). Curriculum counter-strokes and strokes: Swimming in non-existent epistemological rivers.Policy Futures in Education.13, p. 949-967. Doi:10.1177/1478210315579981

Yale Center for Teaching and Learning. Active and Experiential learning Retrievedfrom: http://ctl.yale .edu/teaching/teach ing-how/chapter-4-increasing-critical-thinking-and-motivation/active-andexperiential-learning

Kolb, D. A. (1984). Experiential learning: Experience as the source of learning and development (Vol. 1). Englewood Cliffs, NJ: Prentice-Hall.

Lilley, K., Barker, M., \& Harris, N. (2015).Exploring the process of global citizen learning and the student mind-set. Journal of Studies in International Education. Vol. 19 (3), p. 225-245.

Doi: $10.1177 / 1028315314547822$

McDonald, V. (2010). McDonald, V. (2010). Before and after case studies. In Mills, A. (Ed). Encyclopedia of Case Study Research. Thousand Oaks, California: SAGE Publications.

Moll, L. C., Amanti, C., Neff, D., \& Gonzalez, N. (1992). Funds of knowledge for teaching: Using a qualitative approach to connect homes and classrooms. Theory into Practice, 31(2), 132-141.

NAHO (National Aboriginal Health Organization Canada). (2006). Cultural competency and safety in First Nations, Inuit, and Metis health care. Retrieved from:

http://www.naho.ca/documen ts/naho/english/f actSheets/culturalCompetency.pdf

NCNZ (Nursing Council of New Zealand). (2011). Guide to cultural safety, the Treaty of Waitangi and Maori health in nursing education and practice. Wellington, NZ: NCNZ. Retrieved September 12, 2011.

Ontario Ministry of Education. (2014). Ideas into action. In Ontario Leadership Strategy, Bulletin \#2, Winter 2013-14. Queen's printer for Ontario, Pub.Retrieved from: http://www.edu.gov. on.ca/eng/policyfu nding/leadership/IdeasIntoActionBulletin2.pdf

Ramsden, I. (2005). Toward cultural safety. In Cultural safety in Aetearoa, New Zealand.D.Wepa(Ed.). Auckland, NZ: Pearson Education, pp. 2-19.

Regan, P. (2010). Unsettling the settler within: Indian residential schools, truth telling, and reconciliation in Canada. Vancouver, BC: University of British Columbia Press.

Ryan, M. (2013). The pedagogical balancing act: teaching reflection in higher education. Teaching in Higher Education. Vol. 18, 2, p.144-155. Doi: 10.1080/13562517.2012.694104.

Santos, B. (2014) Epistemologies of the south: Justice against epistemicide. Boulder, Colorado: Paradigm Publishers.

Solomon, R. P., Singer, J., Campbell, A., Allen, A., and Portelli, P. (2011). Brave new teachers: Doing social justice work in neo liberal times. Toronto: Canadian Scholars' Press, Inc.

Tuhiwai Smith, L. (2006). Decolonizing methodologies: Research and Indigenous peoples. Dunedin: University of Otago Press.University of Northern British Columbia faculty of education (elementary) Retrieved from: http://www.unbc.ca/calendar/undergraduate/education\#elementary

UNBC. (2016). Update Magazine. Spring 2016, p. 17.

Wilson, S. (2008). Research is ceremony: Indigenous research methods. Winnipeg: Fernwood Publishing.

Wong, A. (2016) Considering reflection from the student perspective in higher education. Sage Open. January -March 2016: 1-9 . DOI 10.117712158244016638706

Zeichner, K. (2005). Chapter 12: A research agenda in Teacher Education. In Cochran-Smith, M. \& Zeichner, K. (Eds.).Studying teacher education: A report of the AERA panel on Research and Teacher Education. Mahwah, New Jersey: Lawrence Erlbaum Associates. 